\title{
Efficacy and safety of outpatient treatment with direct oral anticoagulation in pulmonary embolism
}

\author{
R. Ghazvinian ${ }^{1}$ (1) - A. Gottsäter ${ }^{1}$ ·. L. Elf ${ }^{1}$
}

Published online: 5 January 2018

(c) The Author(s) 2018. This article is an open access publication

\begin{abstract}
Anticoagulant treatment of acute pulmonary embolism (PE) has traditionally been hospital-based. The lesser need for monitoring with the increasingly used direct acting oral anticoagulants (DOAC) in comparison to warfarin potentially facilitates outpatient treatment of PE with these drugs. This study aimed to evaluate efficacy and safety of outpatient treatment of PE with DOAC. We extracted data from the Swedish quality registry for patients on oral anticoagulation (AuriculA) for all 245 patients in the southernmost hospital region in Sweden (1.3 million inhabitants) selected for outpatient treatment with of PE with DOAC during 2013-2015. Comorbidites, risk factors, and simplified pulmonary embolism severity index were evaluated at baseline, and death, recurrent venous thromboembolism (VTE), and bleeding was recorded during 6 months of follow-up. Outpatient treatment was defined as discharge from the emergency department within $24 \mathrm{~h}$. During 6 months of follow-up, one patient died during DOAC therapy, the cause of death was unrelated to VTE. No VTE recurrences occured, whereas, one patient experienced major bleeding, and five patients experienced minor bleedings. Outpatient treatment of PE with DOAC is efficient and safe in selected patients.
\end{abstract}

Keywords Outpatient treatment $\cdot$ Pulmonary embolism $\cdot$ Direct oral anticoagulant $\cdot$ Venous thromboembolism

\begin{tabular}{|c|c|}
\hline \multicolumn{2}{|c|}{ Abbreviations } \\
\hline $\mathrm{AC}$ & Anticoagulant \\
\hline CTPA & $\begin{array}{l}\text { Computed tomography of the pulmonary } \\
\text { arteries }\end{array}$ \\
\hline $\mathrm{CVC}$ & Central venous catheter \\
\hline DOAC & Direct acting oral anticoagulant \\
\hline DVT & Deep vein thrombosis \\
\hline ED & Emergency department \\
\hline ICD & International classification of diseases \\
\hline LMWH & Low molecular weight heparin \\
\hline $\mathrm{OC}$ & Oral contraceptive \\
\hline PE & Pulmonary embolism \\
\hline PESI & Pulmonary embolism severity index \\
\hline sPESI & $\begin{array}{l}\text { Simplified pulmonary embolism severity } \\
\text { index }\end{array}$ \\
\hline
\end{tabular}

R. Ghazvinian

Raein.Ghazvinian@skane.se

A. Gottsäter

Anders.Gottsater@med.lu.se

J. L. Elf

Johan.Elf@skane.se

1 Division of Vascular Medicine, Skåne University Hospital, Ruth Lundskogs Gata 10, 20502 Malmö, Sweden

$$
\begin{array}{ll}
\text { VTE } & \text { Venous thromboembolism } \\
\text { V/P SPECT } & \text { Ventilation/perfusion single photon emis- } \\
& \text { sion computed tomography }
\end{array}
$$

\section{Introduction}

Venous thromboembolism (VTE), including deep vein thrombosis (DVT) and pulmonary embolism (PE) affects 5\% of the population during their lifetime [1]. Patients with VTE are treated with anticoagulant (AC) therapy for a minimun of 3 months to prevent thrombus extension, embolization, and recurrences $[1,2]$. Hereafter, the decision to stop or continue treatment depends on the balance between the risks of recurrence (1-10\% per year) and bleeding (2-4\% per year) [1].

Anticoagulant treatment of acute PE has traditionally been hospital based, with a mean hospital stay of 6 days [3]. Outpatient treatment of PE has been studied already in the 1990s [4] and current international guidelines suggest outpatient treatment for selected low-risk patientes [5], however, the proportion of patients recieving outpatient treatment is still low in most industrialized countries [6]. Different eligibility criteria for outpatient treatment have been used [7-9]. The most well known, the pulmonary 
embolism severity index (PESI), has been evaluated in a prospective randomised study [10], and the simplified more user-friendly form of PESI (sPESI) compares favorably with the original variant retrospectively [11].

During recent years several direct acting oral anticoagulants (DOAC) with a favorable risk profile have been increasingly used as an alternative to warfarin for VTE treament [12-18]. As the need for monintoring of DOAC treatment is less than for warfarin $[18,19]$, outpatient treatment of VTE is potentially facilitated by DOAC use. DOAC are nowadays considered as first alternative for DVT in the lower extremities and for in hospital treatment of uncomplicated PE [5], but the safety and efficacy of using DOAC for outpatient treatment of PE has only been evaluated in a small material [20].

VTE patients recruited for randomized controlled trials of AC treatment generally have lower bleeding and recurrence rates than patients in clinical practise, and real life data are therefore valuable for clinical decisions upon $\mathrm{AC}$ treatment. In the Swedish quality registry for AC treated patients, AuriculA [21], 25\% of the patients currently use DOAC, the indication being VTE in $15-20 \%$. We have previously evaluated results of home-treatment with warfarin in 307 PE patients without noticing unacceptably high complication risks [22]. We now used AuriculA data to clarify risks for VTE recurrence, death, and bleeding during 6 months in 245 consecutively registered patients with acute PE selected for outpatient treatment with DOAC.

\section{Methods}

\section{Patients}

We extracted data from AuriculA [21] for all 881 patients in the southernmost hospital region in Sweden (1.3 million inhabitants) treated with DOAC for PE (international classification of diseases, tenth-revision [ICD-10] diagnosis codes I26.9 and I26.0) during 2013-2015, a period during which DOAC were gradually replacing warfarin as first line PE treatment. The eight hospitals in the region, out of which one is a tertiary academic hospital, use a flow chart with pragmatic criteria for selection of PE patients suitable for outpatient treatment (Fig. 1). Digital patient files revealed that 245 of the 881 (28\%) patients treated with DOAC had been selected for outpatient treatment, i.e., DOAC treatment had been started already during an emergency department (ED) visit not exceeding $24 \mathrm{~h}$.

The following baseline data were retreived from files and imaging databases: symptoms, comorbidities, referral pathway, diagnostic method [computed tomography of the pulmonary arteries (CTPA) or ventilation/perfusion single photon emission computed tomography (V/P SPECT)], sPESI score [11], malignancies diagnosed prior to or at diagnosis of $\mathrm{PE}$, use of central venous catheters (CVC) or oral contraceptives (OC), pregnancy or postpartum state (defined as the first 6 weeks after delivery), and family history defined as VTE in first or second degree relatives, immobilization defined as $\geq 3$ days of bedrest, trauma or major surgery, flight travel of $>5 \mathrm{~h}$, cast therapy within the
Fig. 1 Flow chart used at our institution for selection of patients with PE suitable for outpatient treatment

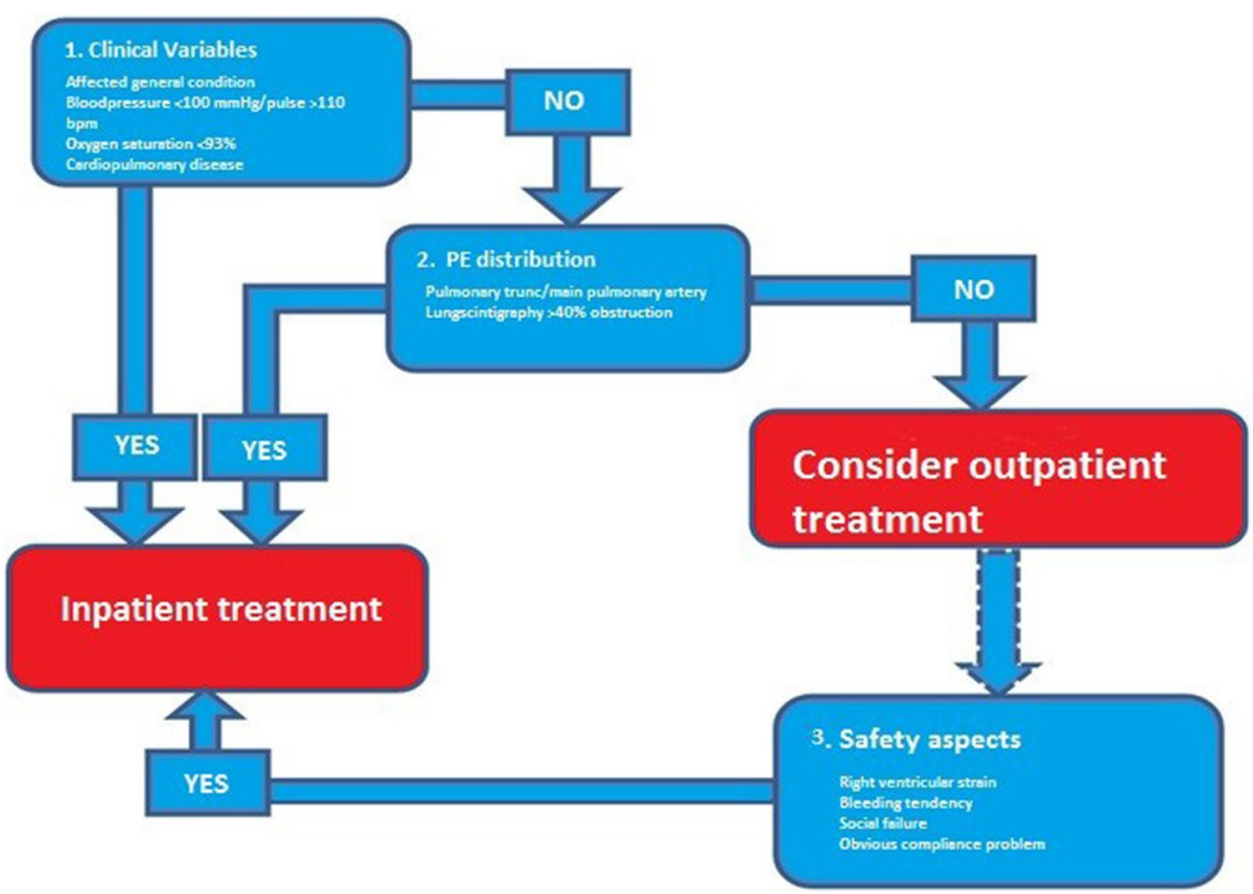


previous month, thrombophilia, ongoing tobacco use, varicose veins or thrombophlebitis, D-dimer [23] (defined as positive if $>0.25 \mathrm{mg} / \mathrm{L}$ ), troponin $\mathrm{T}$ [24] (defined as positive if $>5 \mathrm{ng} / \mathrm{L}$ ).

Data on mortality, recurrent VTE, and bleeding complications (defined according to the International Society on Thrombosis and Haemostasis [25]) during 6 months after diagnosis had been adjudicated by AuriculA officers before entry into the registry, and files and imaging data for all 881 patients were hereafter reviewed by the authors.

\section{Statistical analysis}

Only descriptive statistics were calculated, using SPSS for Windows, version 23.0 (SPSS Inc, Chicago, IL). Results are expressed as mean $\pm \mathrm{SD}$ or $\mathrm{n}(\%)$.

\section{Results}

Baseline characteristics are shown in Table 1. Two of our patients were in week 9 of pregnancy at the time of $\mathrm{PE}$ diagnosis, contraindicating DOAC therapy $[4,18,19]$. In one woman, termination of pregnancy was already planned before PE was diagnosed, however, and in the other case this decision was made at the ED visit before initiation of DOAC.

The majority of patients [238 (97\%)] were treated for 6 months, whereas DOAC therapy was stopped after 3 months in seven patients. During 6 months of follow-up, one patient died; a 72 years old male patient with cardiac arrest of unknown cause during ongoing treatment with rivaroxaban. Acute echocardiography during rescuscitation showed no dilatation of the right ventricle, but the patient's relatives declined autopsy.

In total, nine patients underwent objective imaging for suspected recurrent PE during follow up, but no patient was diagnosed with recurrent VTE.

One patient experienced major bleeding during DOAC therapy; a 61 year old male patient was admitted because of haemothorax caused by pneumonia and longlasting cough during DOAC therapy. This caused a reduction of $20 \mathrm{~g} / \mathrm{L}$ in hemoglobin level, but the patient was hemodynamically stable. He underwent a negative investigation for underlying malignancy, and treatment was changed from DOAC to low molecular weight heparin (LMWH).

Minor bleedings occurred in 5 (2\%) patients during follow-up, one patient with repeated epistaxis, one with increased menstrual bleeding, two with macroscopic haematuria, and one with minor gastrointestinal bleeding (Tables 2 , $3)$.

During 6 months follow-up, previously unknown malignancies were unveiled in three of the patients with minor bleeding;
Table 1 Characteristics of 245 patients in the Skåne region treated with direct oral anticoagulants (DOAC) because of PE during 2013$2015, \mathrm{n}(\%)$ or mean \pm SD

\begin{tabular}{|c|c|}
\hline Patient characteristics & $n=245$ \\
\hline Male/female gender & $125(51) / 120(49)$ \\
\hline Age (years) & $60.0 \pm 17.2$ \\
\hline Previous DVT & $17(7)$ \\
\hline Previous PE & $3(1)$ \\
\hline Varicose veins or trombophlebitis & $17(7)$ \\
\hline \multicolumn{2}{|l|}{ Concomitant diseases } \\
\hline DVT & $3(1)$ \\
\hline Congestive heart failure & $27(11)$ \\
\hline COPD & $11(5)$ \\
\hline \multicolumn{2}{|l|}{ Referral pathway } \\
\hline From primary care & $43(18)$ \\
\hline From hospital & $25(10)$ \\
\hline \multicolumn{2}{|l|}{ Predisposing factors for VTE } \\
\hline Pregnancy or post partum ${ }^{\mathrm{a}, \mathrm{b}}$ & $2(2)$ \\
\hline Surgical intervention & $15(6)$ \\
\hline Cast therapy & $8(3)$ \\
\hline Immobilisation & $35(14)$ \\
\hline Travel $>5 \mathrm{~h}$ & $18(7)$ \\
\hline Hormone therapy ${ }^{\mathrm{a}}$ & $23(9)$ \\
\hline Ongoing tobacco use & $46(19)$ \\
\hline Family history of VTE & $27(11)$ \\
\hline $\mathrm{PVC}$ or CVC & $2(1)$ \\
\hline Active malignancy & $14(6)$ \\
\hline Trauma or fracture & $12(5)$ \\
\hline Thrombophilia & $29(12)$ \\
\hline \multicolumn{2}{|l|}{ Symptoms at admission } \\
\hline Chest pain & $121(49)$ \\
\hline Effort dyspnea & $178(73)$ \\
\hline Cough & $19(8)$ \\
\hline Leg pain & $42(17)$ \\
\hline Other pain & $24(10)$ \\
\hline Incidental PE & $29(12)$ \\
\hline \multicolumn{2}{|l|}{ Investigations } \\
\hline D-dimer positive & $107(44)$ \\
\hline D-dimer NA & $89(36)$ \\
\hline TNT positive $^{\mathrm{c}}$ & $110(45)$ \\
\hline TNT NA & $57(23)$ \\
\hline CTPA & $194(79)$ \\
\hline V/P SPECT & $51(20)$ \\
\hline CTPA and V/P SPECT & $2(1)$ \\
\hline Echocardiography & $48(20)$ \\
\hline \multicolumn{2}{|l|}{ Risk stratification, sPESI score } \\
\hline 0 & $127(52)$ \\
\hline 1 & $98(40)$ \\
\hline 2 & $18(7)$ \\
\hline 3 & $1(0.4)$ \\
\hline 4 & $1(0.4)$ \\
\hline
\end{tabular}


Table 1 (continued)

$\overline{C O P D}$ Chronic obstructive pulmonary disease, CTPA computed tomography of pulmonary arteries, $C V C$ central venous catheter, $D V T$ deep venous thrombosis, Echo echocardiography, $E D$ emergency department, $N A$ not available, $s P E S I$ simplified pulmonary embolism severity index, $P V C$ peripheral venous catheter, VIP SPECT ventilation/perfusion single photon emission computed tomography, VTE venous thromboembolism

${ }^{\text {a }}$ Percentages of female patients only

${ }^{\mathrm{b}}$ Treatment after decision to terminate pregnancy

${ }^{\mathrm{c}}$ Percentages of patients analyzed

Table 2 Treatment data in 245 patients in the Skåne region treated with direct DOAC because of PE during 2013-2015, $n$ (\%)

\begin{tabular}{ll}
\hline & Total \\
\hline Treatment for 6 months & $238(97)$ \\
$<6$ months & $7(3)$ \\
Dabigatran $^{\mathrm{a}}$ & $2(1)$ \\
Rivaroxaban $^{\mathrm{a}}$ & $225(92)$ \\
Apixaban $^{\mathrm{a}}$ & $23(9)$ \\
\hline
\end{tabular}

a Three patients changed from rivaroxaban to apixaban and one patient from rivaroxaban to dabigatran

Table 36 months follow-up of 245 patients in the Skåne region treated with direct DOAC because of PE during 2013-2015, $n$ (\%)

\begin{tabular}{ll}
\hline At 6 months & Total, $n=245$ \\
\hline Death & $1(0,4)$ \\
Major bleeding & $1(0.4)$ \\
Minor bleeding & $5(2)$ \\
Objective imaging for recurrent PE & $9(4)$ \\
Recurrent VTE & $0(0)$ \\
Newly detected malignancy & $3(1)$ \\
\hline
\end{tabular}

$D V T$ Deep venous thromboembolism, $E D$ emergency department

one gastrointestinal malignancy in an 82 years old male with GI-bleeding, one prostatic and one urinary bladder carcinoma in two male patients, 66 and 73 years old, with macroscopic hematuria.

Change of therapy because of side effects was considered necessary in five; three patients changed from rivaroxaban to apixaban, one from rivaroxaban to dabigatran, and one from rivaroxaban to warfarin.

\section{Discussion}

As DOAC are both effective [4, 12-19] and safe [4, 12-18] for VTE treatment, they are already recommended as first treatment option [4] both in patients treated for DVT in the lower limb and hemodynamically stable patients with PE.

Our retrospective study indicates that DOAC can also be used for outpatient treatment of PE with acceptable efficacy and safety in low risk patients. Current practice of routine hospitalization in this group can therefore be challenged.

The definition of outpatient treatment in our study was the same as in the HESTIA study [7], patients discharged within $24 \mathrm{~h}$ after the diagnosis of PE. This definition can be challenged, however. In meta-analysis [8], Zondag identified 13 studies of outpatient treatment of PE with warfarin and LMWH in which the $24 \mathrm{~h}$ limit had been applied, and five other studies defining early discharge as within $72 \mathrm{~h}$ after admission. None of these studies included patient on DOAC therapy, however. Hereafter, Roy et al. published a systematic review of three meta-analyses and 23 studies [6], involving 3671 patients managed at home $(n=3036)$ or discharged early $(n=535)$. Unfortunately, the definition of early discharge was not always clearly defined. The studies reviewed [6] were also heterogenously concerning inclusion criteria and treatment method, and only one study reported on 35 patients treated with DOAC [20].

All studies had at least 3 months of follow-up, with a $<2 \%$ overall rate of thromboembolic reccurrences and $<3 \%$ of major bleeding. In our study we report no thromboembolic reccurences and only one case $(0.4 \%)$ of major bleeding.

As the previous studies were almost exclusively performed with warfarin and LMWH, however, our data should not be directly compared to previously published figures. Other important differences between our and previously published materials $[6,8]$ are patient gender, age, prevalence of concomitant malignancy, and duration of follow-up.

Different patient materials also differ regarding the sets of criteria for selection of PE patients suitable for outpatient treatment. We used a modified [22] version of the sPESI score [11], a validated approach in this respect [26-28]. In previous studies information on PESI or sPESI classification is not always available, and in some cases the HESTIA criteria [7] have been used instead. Apparently both these two methods for patient selection can be used with satisfactory results, and a scientific comparison of the two methods is currently ongoing (clinicaltrials.gov identifier: NCT02811237). Our more pragmatic selection criteria seems to identify more patients suitable for outpatient treatment compared with sPESI since $48 \%$ of our study cohort had a non low risk score according to sPESI.

A recent study [29] documented that observation stay, defined as less than 2 days in hospital, was associated with 
reduced costs compared to conventional inpatient treatment of PE. Furthermore, observation stay was associated with a lower risk for development of hospital-acuqired conditions, whereas death rates, need for thrombolysis, and readmission rate did not differ [29]. Our definition of outpatient treatment as only up to $24 \mathrm{~h}$ in hospital might potentially be associated with further savings, and the economic consequences of our strategy will be further evaluated.

The major limitations of the study are its retrospective nature, and the lack of randomization. The selection of patients, both for DOAC instead for warfarin treatment, and for outpatient instead of inpatient treatment of course constitutes another limitation of our study. Our results should therefore not be applied to PE patients in general. According to established criteria for treatment of PE [5], however, a selection process is necessary before patients are recommended outpatient treatment. This fact precludes propensity scoring for comparisons between out- and in-patients with PE. Prospective randomized studies of outpatient treatment of low risk PE patients are indeed warranted.

In conclusion, our 6 month follow-up study showed that outpatient treatment of PE with DOAC is efficient and safe in selected low risk patients with PE.

Author contributions RG, AG, and JE all contributed to the study concept and design, acquisition of data, data analysis, intepretation, drafting, and critical revision of the manuscript. Statistical analysis was performed by RG.

\section{Compliance with ethical standards}

Conflict of interest The authors state that they have no conflicts of interests.

Ethical approval All procedures performed in studies involving human participants were in accordance with the ethical standard of the institutional and/or national research committe and with the 1964 Helsinki declaration and its later amendments or comparable ethical standards.

Open Access This article is distributed under the terms of the Creative Commons Attribution 4.0 International License (http://creativecommons.org/licenses/by/4.0/), which permits unrestricted use, distribution, and reproduction in any medium, provided you give appropriate credit to the original author(s) and the source, provide a link to the Creative Commons license, and indicate if changes were made.

\section{References}

1. Guyatt GH, Akl EA, Crowther M, Gutterman DD, Schuünemann HJ, American College of Chest Physicians, Antithrombotic therapy and prevention of thrombosis (2012) American college of chest physicians evidence-based clinical practice guidelines. Chest 141:7-47
2. Yeh C, Gross P, Weitz J (2014) Evolving use of new oral anticoagulants for treatment of venous thromboembolism. Blood 124:1020-1028

3. Aujesky D, Stone RA, Kim S et al (2008) Length of hospital stay and postdischarge mortality in patients with pulmonary embolism: a statewide perspective. Arch Intern Med 168:706-712

4. Wells PS, Kovacs MJ, Bormanis J, Forgie MA, Goudie D, Morrow B, Kovacs J (1998) Expanding elegibility for outpatient treatment of deep vein thrombosis and pulmonary embolism with lowmolecular-weight-heparin: a comparison of patient self-injection with homecare injection. Arch Intern Med 158:16:1809-1812

5. Kearon C, Akl EA, Ornelas J, Blaivas A, Jimenez D, Bounameaux H, Huisman M, King CS, Morris TA, Sood N, Stevens SM, Vintch JRE, Wells P, Woller SC, Moores L (2016) Antithrombotic therapy for VTE disease CHEST guideline and expert panel report. Chest 149:2:315-352

6. Roy PM, Moumneh T, Penaloza A, Sanchez (2017) Outpatient management of pulmonary embolism. Thromb Res 157:92-100

7. Zondag W, Mos ICM, Creemers-Schild D, Hoogerbrugge ADM, Dekkers OM, Dolsma J, Eijsvogel M, Faber LM, Hofstee HMA, Hovens MMC, Jonkers GJPM, Van Kralingen KW, Kruip MJHA, Vlasveld T, De Vrede MJM, Huisman MV, HESTIA Study Investigators (2011) Outpatient treament in patients with acute pulmonary embolism: the HESTIA study. J Thromb Haemost 9:8:1500-1507

8. Zondag W, Kooiman J, Klok FA, Dekkers OM, Huisman MV (2013) Outpatient versus inpatient treatment in patients with pulmonary embolism: a meta-analysis. Eur Respir J 42:134-144

9. Den Exter PL, Zondag W, Klok FA, Brouwer RE, Dolsma J, Eijsvogel M, Faber LM, Van Gerwen M, Grootenboers MJ, HellerBaan R, Hovens MM, Jonkers GJPM, Van kralingen KW, Melissant CF, Peltenburg H, Post JP, Van de Ree MA, Vlasveld LTT, de Vreede MJ, Huisman MV (2016) Efficacy and safety of outpatient treatment based on the HESTIA clincal decision rule with or without N-terminal Pro-Brain natriuretic peptide testing in patients with acute pulmonary emblism, a randomized clinical trial. Am J Respir Crit Care Med 194:8:998-1006

10. Aujesky D, Obrosky SO, Stone AR, Auble TE, Perrier A, Cornuz J, Roy PM, Fine MJ (2013) Derivation and validation of a prognostic model for pulmonary embolism. Eur Heart J 36:1:760

11. Jimenez D, Aujesky D, Moores L, Gomez V, Lobo JL, Uresandi F, Otero R, Monreal M, Muriel A, Yusen RD, RIETE Investigators (2010) Simplification of the pulmonary embolism serverity index for prognostication in patients with acute symptomatic pulmonary embolism. Arch Intern Med 170:15:1389 - 138

12. Schulman S, Kearon C, Kakkar AK et al (2009) Dabigatran versus warfarin in the treatment of acute venous thromboembolism. N Engl J Med 361:24:2342-2352

13. Bauersachs R, Berkowitz SD, Brenner B et al (2010) Oral rivaroxaban for symptomatic venous thromboembolism. N Engl J Med 363:26:2499-2510

14. Hokusai-VTE I12nvestigators, Buller HR, Decousus $\mathrm{H}$ et al (2013) Edoxaban versus warfarin for the treatment of symptomatic venous thromboembolism. N Engl J Med 369:15:1406-1415

15. Agnelli G, Buller HR, Cohen A et al (2013) Oral apixaban for the treatment of acute venous thromboembolism. N Engl J Med 369:9:799-808

16. Investigators EINSTEIN-EP, Buller HR, Prins MH et al (2012) Oral rivaroxaban for the treatment of symptomatic pulmonary embolism. N Engl J Med 366:14: 1287-1297

17. van Es N, Coppens M, Schulman S, Middeldorp S, Buller HR (2014) Direct oral anticoagulants compared with vitamin K antagonists for acute venous thromboembolism: evidence from phase 3 trials. Blood 124:12:1968-1975 
18. Comerota AJ, Ramacciotti E (2016) A comprehensive overview of direct oral anticoagulants for the management of venous thromboembolism. Am J Med Sci 352:92-106

19. Piran S, Schulman S (2016) Management of venous thromboembolism: an update. Thromb J 14:1: 23

20. Beam DM, Kahler ZP, Kline JA et al (2015) Immediate discharge and home treatment with rivaroxaban of low-risk venous thromboembolism diagnosed in two U.S. emergency departments: a one-year preplanned analysis. Acad Emerg Med 22:7

21. Wieloch M, Själander A, Frykman V, Rosenqvist M, Eriksson N, Svensson PJ (2011) Anticoagulation control in Sweden: reports of time in therapeutic range, major bleeding, and thrombo-embolic complications from the national quality registry AuriculA. Eur Heart J 32:2282-2289

22. Elf JE, Jögi J, Bajc M (2015) Home treatment of patients with small to medium sized acute pulmonary embolism. J Thromb Thrombolysis 39:2:166-172

23. Elf JL, Strandberg K, Nilsson C, Svensson PJ et al (2009) Clinical probability assesment and D-dimer determination in patients with suspected deep vein thrombosis, a prospective multicenter management study. Thromb Res 123:612-616

24. Daquarti G, Vecchio NM, Mitrione CS, Furmento J, Ametrano MC, Pace MPD, Costabel JP et al (2016) High-sensitivity troponin and right ventriuclar function in acute pulmonary embolism. Am J Emerg Med 32:1579-1582

25. Schulman S, Angeras U, Bergqvist D, Eriksson B, Lassen MR, Fisher W, Subcommittee on Control of Anticoagulation of the
Scientific and Standardization Committee of the Internation Society on Thrombosis and Haemostasis (2010) Definition of major bleeding in clinical investigations of antihemostatic medicinal products in non-surgical patients. J Thromb Haemost 8:202-204

26. Aujesky D, Roy PM, Verschuren F, Righini M, Osterwalder J, Egloff M, Renaud B, Verhamme P, Stone RA, Legell C, Sanchez O, Pugh NA, N`gako A, Cornuz J, Hugli O, Beer HJ, Perrier A, Fine MJ, Yealy DM (2011) Outpatient versus inpatient treatment for patients with acute pulmonary embolism: an international, open-label, randomised, non-inferiority trial. Lancet 378:41-48

27. Beer JH, Burger M, Gretener S, Bernard-Bagattini S, Bounameaux $\mathrm{H}$ et al (2003) Outpatient treatment of pulmonary embolism is feasible and safe in substantial proportion of patients. J Thromb Haemost 1:186-187

28. Agterof MJ, Schutgens RE, Snijder RJ, Epping G, Peltenburg HG, Posthuma EF, Hardeman JA, Van der Griend R, Koster T, Prins MH, Biesma DH et al (2010) Out of hospital treatment of acute pulmonary embolism in patients with a low NT-proBNP level. J Thromb Haemost 8:1235-1241

29. Weeda RE, Peacock WF, Fermann GJ, Wells PS, Ashton V, Crivera C, Bunz TJ, Wildgoose P, Schein JR, Coleman CI et al (2016) Outcomes associated with observation stays versus inpatient admissions for pulmonary embolism. J Thromb Thrombolysis 42:513-519 